\title{
Sediment oxygen demand in streams: lab measurements underestimate in situ rates substantially
}

\author{
Erik Jeppesen ${ }^{1,2,3,4^{*}}$, Torben Moth Iversen ${ }^{1 * *}$ and Tserenpil Sh ${ }^{5}$ \\ ${ }^{1}$ Department of Ecoscience, Aarhus University, Silkeborg, Denmark \\ ${ }^{2}$ Sino-Danish Centre for Education and Research (SDC), Beijing, China \\ ${ }^{3}$ Limnology Laboratory, Department of Biological Sciences and Centre for Ecosystem \\ Research and Implementation, Middle East Technical University, Ankara, Turkey \\ ${ }^{4}$ Institute of Marine Sciences, Middle East Technical University, Mersin, Turkey \\ ${ }^{5}$ Nuclear Research Center, National University of Mongolia, Ulaanbaatar, Mongolia \\ * Corresponding author: ej@ecos.au.dk; ORCID ID: 0000-0002-0542-369X \\ ${ }^{* *}$ Deceased
}

Received: 02 December 2021; revised: 20 December 2021; accepted: 22 December 2021

\begin{abstract}
Global warming is expected to affect stream metabolism significantly; and higher temperatures may lead to higher respiration and thus higher risk of oxygen depletion. It is, therefore, crucial to obtain reliable data on the oxygen dynamics in the different stream compartments. Determination of sediment oxygen demand (SOD) is typically based on lab or field measurement using cores or benthic chamber in which the actual physical conditions in the streams are not possible to mimic perfectly. We compared SOD based on lab core incubations with SOD measured in situ in stream sections where the oxygen exchange between water and air was eliminated artificially. The in situ SOD increased with increasing oxygen concentrations and both the temperature and the oxygen dependency of SOD increased with increasing organic content in the surface sediment. The laboratory rates reached $17-83 \%$ of the rates obtained in situ. The percentages were especially low at low stream velocity, likely reflecting a pure imitation of the physical conditions near the sediment in the lab when the sediment organic content was high (at low velocity). Therefore, alternative methods, simulating the natural horizontal water flow, are needed to provide reliable information on SOD in streams.
\end{abstract}

Keywords: Metabolism, running waters, sediment, water, oxygen

\section{INTRODUCTION}

Global warming is expected to affect the metabolism and oxygen concentrations in natural streams. Higher temperature may lead to higher respiration of biota and thus a higher risk of oxygen depletion. To predict the effects of a warming climate, accurate measurements of the oxygen dynamics in the different stream compartments, e.g., water, sediment and macrophytes, are needed. Sediment oxygen demand (SOD) is an important part of the stream metabolism [1, 2]. To estimate SOD, various approaches have been used, including laboratory and in situ incubation of various kinds [2-5]. None of these methods could fully mimic the stream dynamics as the lateral flow cannot be readily simulated $[2,4]$. An alternative is to set up tunnel systems in the streams or flow-through systems in the lab [6,7], but both systems are complicated to establish and handle. Several studies have compared the results of the different approaches [2, 8], and it is evident that the tunnel method often yields higher values than the core and in situ respirometer methods [2]. However, in the conducted studies, the true stream SOD was unknown, hampering a full evaluation of how well the methods mimicked the actual rates. Some studies have compared SOD based on incubations with oxygen consumption calculated from upstream-downstream oxygen mass balances requiring correction for reaeration, the latter based on empirical equations. However, as these re-aeration equations are quite uncertain [4, 9], the field estimates of SOD might not be accurate. We conducted a comparative study of a widely used laboratory incubation core method with mass balance data. To overcome the problem with reaeration, we established a simplified system, where re-

(C) The Author(s). 2021 Open access. This article is distributed under the terms of the Creative Commons Attribution 4.0 International License (http://creativecommons.org/licenses/by/4.0/), which permits unrestricted use, distribution, and reproduction in any medium, provided you give appropriate credit to the original author(s) and the source, provide a link to the Creative Commons license, and indicate if changes were made. 
aeration was eliminated by covering the stream surface with a plastic film during the experiment.

It is well established that SOD is dependent on the temperature, oxygen concentration and organic matter in the sediment [10]. Although, the relationships established are all based on measurements in incubation chambers. To what extent such relationships can be transferred to the field is an open question given the different physical conditions mentioned above. Therefore, our second aim was to re-examine the dependence of the field estimated SOD on the oxygen concentration, temperature and sediment organic matter content.

\section{EXPERIMENTAL}

Study area and in situ experimental set-up: This study was performed in the upper part of the River Suså, which is situated on Southern Zealand, Denmark [11]. The river runs through agricultural areas and receives a moderate amount of sewage, mainly from diffuse sources. Three $75 \mathrm{~m}$ long stream sections were chosen, varying in surface slope from 0.39 to $1.18 \mathrm{~km}^{-1}$ (Table 1).

Table 1. Hydraulic and hydrometric data for the three sections studied in the Suså watershed in July-October

\begin{tabular}{llll}
\hline & Section 1 & Section 2 & Section 3 \\
\hline Surface slope $\left(\mathrm{m} \mathrm{km}^{-1}\right)$ & 0.69 & 0.39 & 1.18 \\
Mean velocity $\left(\mathrm{m} \mathrm{sec}^{-1}\right)$ & $0.14-0.34$ & $0.06-0.12$ & $0.09-0.21$ \\
Mean depth $(\mathrm{m})$ & $0.15-0.25$ & $0.20-0.26$ & $0.14-0.34$ \\
Mean width $(\mathrm{m})$ & 2.5 & 4.0 & 2.0 \\
Discharge $\left(\mathrm{L} \mathrm{sec}{ }^{-1}\right)$ & $49-240$ & $65-136$ & $23-107$ \\
Substratum type & mud, sand & mud, silt & $\begin{array}{l}\text { mud, sand } \\
\text { on silt }\end{array}$ \\
\hline
\end{tabular}
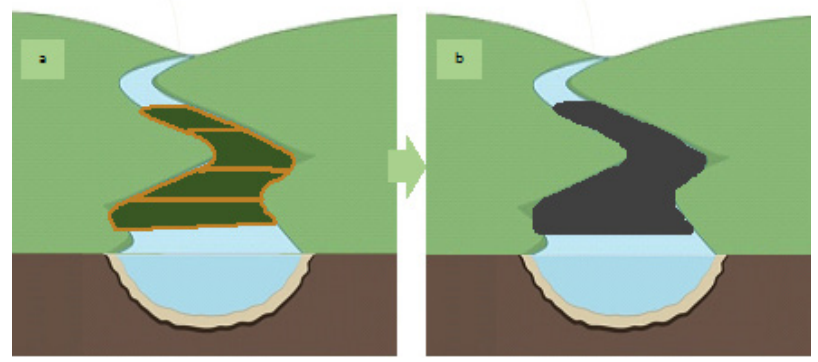

Fig. 1. Diagram of the experimental set-up in situ. a. To prevent plant re-establishment and benthic algal or macrophyte growth, the sections were kept dark by covering the experimental sections of the streams with wood frames $(3.6 \times 5.4 \mathrm{~m})$ with tarpaulins, positioned on the stream banks;

b. To avoid exchange of oxygen between water and air (re-aeration) a plastic film was rolled out on the water surface after removing the wood frames and measurements were conducted in upstream and downstream with the same water mass (see further details in the text).
Sections 1 and 2 were situated in the River Suså itself, whereas section 3 was situated in a small tributary, River Sneslev Lilleå. Variations in stream velocity, depth and discharge during the study are given in Table 1 .

All sections were characterised by dense vegetation of macrophytes and filamentous algae in summer. The study was conducted from June to October. In June, the vegetation of three sections was cut and removed. To prevent plant re-establishment and benthic algal or macrophyte growth, the sections were kept dark by covering the experimental sections of the streams with a number of wood frames $(3.6 \times 5.4 \mathrm{~m})$ with tarpaulins, positioned on the stream banks (Fig. 1a). The sections were adapted to the new conditions for three weeks before initiating the measurements.

In situ measurements: The in situ measurements were conducted over 1-3 diurnal periods (Table 2). In each section, the tarpaulin frames were removed, and a dark polyethylene plastic film with $0.1 \mathrm{~mm}$ thickness was rolled out on the water surface from the downstream to the upstream end of the sections by two persons, one on each bank, to avoid disturbing the sediment (Fig. 1b). The film was fastened at the banks with canes, and all air pockets were removed by pouring water over the film. The oxygen permeability of the plastic film is negligible, and the film can therefore be considered to eliminate re-aeration as well as photosynthesis (under dark condition). Then, the residence time of the water in each section was estimated by injecting an aceticmethanol solution of Rhodamine $B$ in a transversal line $15 \mathrm{~m}$ upstream the beginning of the sections and following the traverse of the substance through the sections. At intervals ( 8 to 19 times during the 1-3 diurnal periods), a water volume was followed from upstream to downstream of the experimental reach, and temperature and oxygen were measured when the water entered and left the plastic covered sections, the latter based on the residence time obtained with the Rhodamine B injections. The oxygen concentration was measured by a chemical method, the Winkler technique [12]. Since re-aeration was eliminated using dark plastic film, the total oxygen consumption could be estimated as the difference in the oxygen transport between the upstream and downstream of the section. The oxygen consumption of the water was estimated from incubations of stream water in $125 \mathrm{ml}$ Jena glass bottles covered with tinfoil based on Winkler titration before and after incubation. Sets of three samples were incubated at different temperatures $\left( \pm 0.5^{\circ} \mathrm{C}\right)$, reflecting the variation in stream temperatures. Turbulence was obtained by magnetic stirring, and the incubation period $(5-15 \mathrm{~h})$ was adjusted to reduce the oxygen concentration by $10-20 \%$. The discharge in the different section was estimated either from measurements of stream velocity with an Ott-propeller or from measurements of residence time and mean depth.

Lab measurements: In the lab, SOD was measured on undisturbed sediment cores taken with Perspex tubes 
(length $40.5 \mathrm{~cm}$, diameter $5.2 \mathrm{~cm}$ and thickness $0.3 \mathrm{~cm}$ ) (Fig. 2). Six to twelve cores were taken randomly in each section on each sampling occasion. The depth of the sediment was $10-15 \mathrm{~cm}$. The cores were placed in the dark at the actual stream temperature $\left( \pm 1.5^{\circ} \mathrm{C}\right)$ not later than $1.5 \mathrm{~h}$ after sampling. About $80 \%$ of the water was replaced by GF/C-filtered $(0.45$ $\mu \mathrm{m})$ stream water without disturbing the sediment. Homogeneity in the water was maintained by a magnetic stirrer, placed outside the core (with a magnet inside) (Fig. 2) as close as possible to the sediment but without disturbing it [13].

Fig. 2. Diagram of the core experimetal system used in the lab. 1. Magnetic stirrer;

2. Cored sediment.

The cores were stirred for about half an hour before they were sealed with rubber corks. Stirring continued during the incubation as well. The incubations lasted for 2-10 $\mathrm{h}$ and a $0.5-1.5 \mathrm{mg} \mathrm{O}_{2} \mathrm{~L}^{-1}$ reduction of the oxygen concentration was obtained. SOD was measured before and after the experiments by Winkler method. The mean concentrations of the two measurements were used to describe the experimental oxygen concentration.

Following the SOD estimates, the upper $3 \mathrm{~cm}$ of the sediment was collected and analysed for ash free dry weight (AFDW) by first drying at $105{ }^{\circ} \mathrm{C}$ to constant weight and then burning at $550^{\circ} \mathrm{C}$ for $6 \mathrm{~h}$. Baity (1938) [14] found only increasing oxygen consumption in the interval 0-3 cm, and others [1] found no changes in the oxygen consumption between 2.5 and $10 \mathrm{~cm}$ in sediments from a river similar to River Suså. The upper $3 \mathrm{~cm}$, therefore, appear to be a reasonable thickness to consider.

\section{RESULTS AND DISCUSSION}

In situ SOD was estimated by subtracting the water oxygen consumption from the total oxygen consumption as found by the in situ mass balances. The water oxygen consumption varied between 1 and $20 \mathrm{mg} \mathrm{O}_{2} \mathrm{~m}^{-2} \mathrm{~h}^{-1}$ and was always 1-2 orders of magnitude lower than SOD (Table 2). The relationship between temperature $\left(\mathrm{T},{ }^{\circ} \mathrm{C}\right)$ and water oxygen consumption $\left(\mathrm{Y}, \mu \mathrm{g} \mathrm{O} \mathrm{O}^{-1} \mathrm{~h}^{-1}\right)$ was $\mathrm{Y}$ $=0.0095 \mathrm{~T}^{3.13}\left(\mathrm{r}^{2}=0.81, \mathrm{n}=34\right)$ based on data from all sections and periods. SOD varied between 0.05 and $1.53 \mathrm{~g} \mathrm{O}_{2} \mathrm{~m}^{-2} \mathrm{~h}^{-1}$ (Table 2) with maximum values in JulyAugust. In all sections, the diurnal variations in SOD were considerable. The maximum values were 2.1-4.8 times higher than the minimum values. As expected, the oxygen consumption was higher when the oxygen concentration and temperature were high (e.g., afternoon) and low when the oxygen concentration and temperature were low (before sunrise) (data not shown).
Table 2. Minimum and maximum values of the in situ oxygen consumption, oxygen concentration and temperature

\begin{tabular}{|c|c|c|c|c|c|}
\hline \multirow[t]{2}{*}{ Date } & \multicolumn{2}{|c|}{$\begin{array}{c}\text { Oxygen } \\
\text { consumption } \\
\left(\mathrm{mg} \mathrm{O}_{2} \mathrm{~m}^{-2} \mathrm{~h}^{-1}\right) \\
\end{array}$} & \multirow[t]{2}{*}{$\begin{array}{c}\text { Oxygen } \\
\text { concentration } \\
\left(\mathrm{mg} \mathrm{O}_{2} \mathrm{~L}^{-1}\right)\end{array}$} & \multirow[t]{2}{*}{$\begin{array}{l}\text { Temp. } \\
\left({ }^{\circ} \mathrm{C}\right)\end{array}$} & \multirow[t]{2}{*}{$\begin{array}{l}\text { Mean } \\
\text { Temp. } \\
\left({ }^{\circ} \mathrm{C}\right)\end{array}$} \\
\hline & Water & Sediment & & & \\
\hline \multicolumn{6}{|l|}{ Section 1} \\
\hline $25-26 / 7$ & $8-20$ & $322-1530$ & $3.9-17.8$ & $16.3-21.1$ & 18.3 \\
\hline $10-13 / 8$ & $3-11$ & $301-831$ & $3.7-10.1$ & $12.2-18.4$ & 15.5 \\
\hline 29/8-1/9 & $2-7$ & $112-459$ & $6.5-10.9$ & $10.4-14.8$ & 11.9 \\
\hline $26-30 / 9$ & $2-6$ & $61-170$ & $9.0-11.5$ & $9.0-12.6$ & 10.9 \\
\hline \multicolumn{6}{|l|}{ Section 2} \\
\hline $10-13 / 8$ & $6-12$ & $100-316$ & 3.3-20.1 & $13.0-16.9$ & 15.0 \\
\hline $29-31 / 8$ & $3-9$ & $104-261$ & 5.3-10.8 & $9.9-14.8$ & 12.4 \\
\hline \multicolumn{6}{|l|}{ Section 3} \\
\hline $10-13 / 8$ & $3-7$ & $84-290$ & $2.6-9.1$ & $11.5-15.3$ & 12.5 \\
\hline $29 / 8-1 / 9$ & $4-6$ & $141-295$ & $3.7-6.9$ & $10.4-12.8$ & 11.6 \\
\hline $27-30 / 9$ & $1-3$ & $53-124$ & $5.2-7.6$ & $8.2-11.0$ & 9.6 \\
\hline $13-15 / 10$ & $1-3$ & $54-161$ & $6.4-9.1$ & $8.8-11.0$ & 9.8 \\
\hline
\end{tabular}

Temperature and especially oxygen concentration showed great diurnal variations (Table 2). The in situ SOD dependency of these two variables in each period and section were, therefore, estimated (least squares fit) from the frequently used equation [15]:

$$
\text { SOD }=a(O x)^{b} \theta^{(\text {temp-20) }}
$$

where: SOD is $\mathrm{mg} \mathrm{O}_{2} \mathrm{~m}^{-2} \mathrm{~h}^{-1}$, oxygen concentration (ox) is $\mathrm{mg} \mathrm{O}_{2} \mathrm{~L}^{-1}$, temperature (temp) is ${ }^{\circ} \mathrm{C}$, and $\mathrm{a}, \mathrm{b}$ and $\theta$ are constants.

The regression coefficients varied between 0.53 and 0.98 (Table 3), being high in periods with pronounced variations in temperature and oxygen concentration and low with small variations. The estimated $\theta$-values varied between 0.97 and 1.20 (Table 3).

Table 3. Linear regression on log-transformed data using Eq. $1 ; r^{2}$ is the determination coefficient, and $a, b, \theta$ are constants. Also shown is the mean water temperature during the periods (for variation see Table 2)

\begin{tabular}{llllll}
\hline & a & b & $\boldsymbol{\theta}$ & $\mathbf{r}^{2}$ & $\begin{array}{c}\text { Mean Temp. } \\
\left({ }^{\circ} \mathbf{C}\right)\end{array}$ \\
\hline Section 1 & & & & & \\
25-26/7 & 208.2 & 0.69 & 1.06 & 0.77 & 18.3 \\
$10-13 / 8$ & 151.4 & 0.77 & 1.06 & 0.76 & 15.5 \\
29/8-1/9 & 19.3 & 1.56 & 1.10 & 0.72 & 11.9 \\
26-30/9 & 24.5 & 0.95 & 1.09 & 0.75 & 10.9 \\
Section 2 & & & & & \\
10-13/8 & 42.3 & 0.62 & 0.97 & 0.83 & 15.0 \\
29-31/8 & 69.0 & 0.74 & 1.08 & 0.85 & 12.4 \\
Section 3 & & & & & \\
$10-13 / 8$ & 88.7 & 0.85 & 1.12 & 0.86 & 12.5 \\
29/8-1/9 & 15.4 & 1.29 & 1.07 & 0.98 & 11.6 \\
$27-30 / 9$ & 7.4 & 2.30 & 1.19 & 0.53 & 9.6 \\
$13-15 / 10$ & 10.5 & 1.88 & 1.20 & 0.55 & 9.8 \\
\hline
\end{tabular}


In section 3, which had highly silty sediment, the $\theta$-values were generally high compared with the other sections. Except for one measurement, there was a tendency to obtain increasing values of $\theta$ with decreasing mean temperature (Table 3 ). The estimated b-values varied between 0.62 and 2.30 (Table 3 ). Both $\theta$ - and b-values varied widely between sections at the same time and in each section with time.

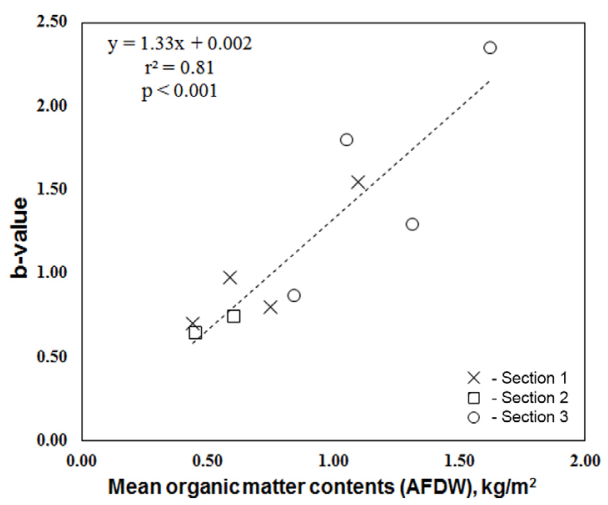

Fig. 3. b-Values (sediment oxygen demand $=$ a (oxygen

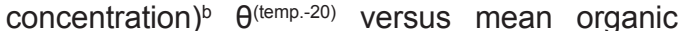
matter contents in the upper $3 \mathrm{~cm}$ of the sediment.

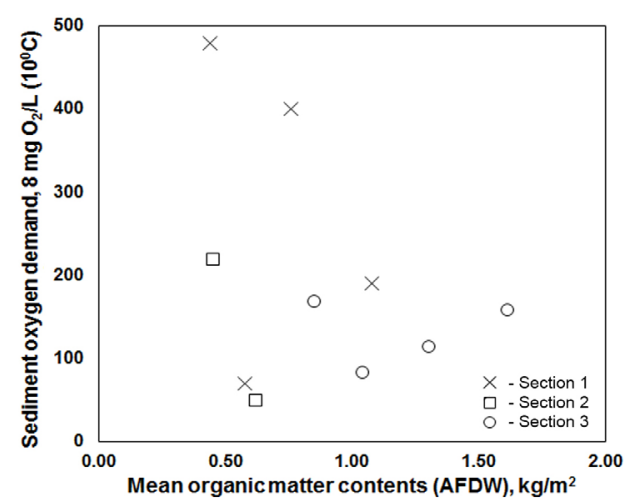

Fig. 4. Sediment oxygen demand $\left(\mathrm{mg} \mathrm{O}_{2} \mathrm{~m}^{-2} \mathrm{~h}^{-1}\right)$ at fixed oxygen concentration and temperature versus mean organic content in the upper $3 \mathrm{~cm}$ of the sediment.

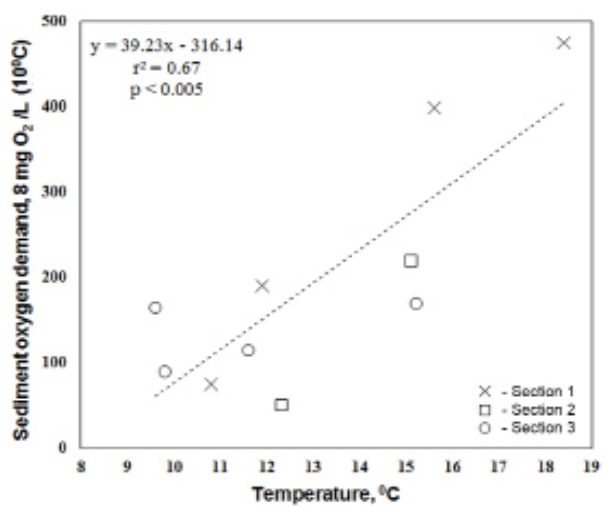

Fig. 5. Sediment oxygen demand $\left(\mathrm{mg} \mathrm{O}_{2} \mathrm{~m}^{-2} \mathrm{~h}^{-1}\right)$ at fixed oxygen concentration and temperature versus temperature in the streams.
The b-values were significantly correlated with the sediment AFDW (Fig. 3), with about $61 \%$ of the variance being explained. SOD was standardised to $10^{\circ} \mathrm{C}$ and $8 \mathrm{mg} \mathrm{O}_{2} \mathrm{~L}^{-1}$ (to be able to compare the results) based on Eq. 1 and the parameters are given in Table 3 for all sections and sampling periods. There was no significant correlation between SOD and sediment AFDW ( $p>0.05)$ (Fig. 4). However, there was a significant decrease in SOD with decreasing temperature (Fig. 5).

For each date and section, the SOD found by the laboratory method was compared to that obtained by the in situ method. The laboratory data were corrected to actual field temperatures and oxygen concentrations using established relationships between laboratory SOD, temperature (temp) and oxygen concentration (ox):

$\mathrm{SOD}=\mathrm{a}(\mathrm{ox})^{0.75} 1.10^{\text {(temp-20) }}\left(\mathrm{n}=37, \mathrm{r}^{2}=0.85, \mathrm{p}<0.001\right)$

In all cases, the laboratory SOD estimates were lower than the in situ estimates, ranging from $17 \%$ to $83 \%$ of the in situ estimates, and the percentage increased significantly with increasing mean stream velocity (Fig. 6).

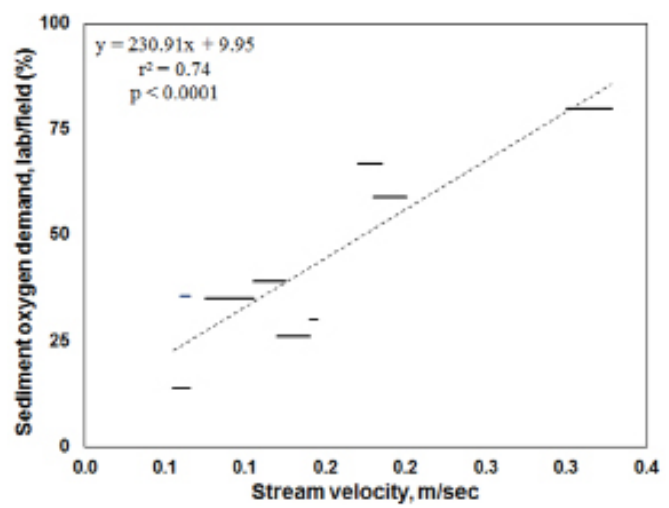

Fig. 6. The relation between laboratory and field measurements of the sediment oxygen demand versus the water velocity in the stream during the field experiments.

In our simplified stream ecosystems without reaeration and photosynthesis, the oxygen consumption of the water was 1-2 orders of magnitude lower than of SOD (Table 2). The low contribution of the oxygen consumption in the water agrees with other studies from natural streams [16]. SOD in small streams during the summer is reported to vary between 0.7 and $82 \mathrm{~g}$ $\mathrm{O}_{2} \mathrm{~m}^{-2} \mathrm{~d}^{-1}$ and mostly ranges within 10-35 $\mathrm{g} \mathrm{O}_{2} \mathrm{~m}^{-2} \mathrm{~d}^{-1}$ [17]. Our findings from streams without macrophytes varied between 0.05 and $1.53 \mathrm{~g} \mathrm{O}_{2} \mathrm{~m}^{-2} \mathrm{~h}^{-1}$ (Table 2), corresponding to 1.3 and $37 \mathrm{~g} \mathrm{O}_{2} \mathrm{~m}^{-2} \mathrm{~d}^{-1}$, and is thus within the range previously reported. In 34 Australian waters [5], however, using an in situ respirometer found overall lower values of 0.1-1.3 (mean 0.6) $\mathrm{g} \mathrm{O}_{2} \mathrm{~m}^{-2} \mathrm{~d}^{-1}$ in systems dominated by benthic algae; and the values between 1 and $7 \mathrm{~g} \mathrm{O}_{2} \mathrm{~m}^{-2} \mathrm{~d}^{-1}$ were recorded in various sections of the Jordan River in Utah using different 
types of in situ respirometers [4]. Thus, their values were overall lower than our field SOD estimates in summer (Table 2).

We found no significant correlation between the level of in situ SOD, at fixed temperature and oxygen concentration, and the sediment AFDW (Fig. 4). This concurs with [18] and [19], while [3] found a significant linear relationship with total organic carbon. Different results may reflect variation in the degradability of the organic matter $[20,21]$, water exchange in the sediment [22] as well as the numbers and activity of the macroinvertebrates present [1].

We found large variations in the oxygen dependency of in situ SOD. The b-values calculated for sections 1 and 2 varied between 0.62 and 1.56 (Table 3 ), although the latter was not significantly greater than 1.0 ( $p>0.05)$. Using a mud core laboratory method, a mean b-value of 0.45 for the sediments from three unpolluted rivers and b-values close to 1.0 in a river polluted with wastewater were found [1], indicating a shift from an oxygen consumption limited by organic matter to a consumption limited by the oxygen concentration, i.e., an approximately 0 order and 1 order reaction, respectively [23]. In another study b-values between 0.30 and 0.66 were found [19].

We found major differences between in situ SOD and the mud core lab method, with decreasing deviance with increasing stream velocity (Fig. 3). This might be explained by the placing of the stirrer in the lab setup. At lower stream velocities, the upper sediment consisted of fine particles, and the stirrer was placed high above the sediment surface to avoid sediment resuspension. This leads to a locally high mixing just below the stirrer and a strong velocity gradient from this point. At higher stream velocities, the upper sediment consisted of coarse particles, and the stirrer was placed just above the sediment surface. Consequently, the velocity gradient across the sediment surface was smaller and probably gave a better simulation of natural stream conditions. Supporting this view, Mackenthun and Stefan (1995), using a lab channel system, found a flow effect on SOD with a major increase in SOD with increasing velocity up to a certain threshold that depended on the type of sediment and biota [24], and with the highest effect of velocity on organic sediment, as in our study. Furthermore, they found that SOD in cores were approximately the same as those obtained with a lab flow-through system when the sediment was sandy [2], but lower when it was organic rich. Others have used closed benthic respirometers of various kinds [2-5], but such chamber systems are also sensitive to resuspension if the sediment is organic rich, and the stirring has to be adjusted accordingly. Thus, in a comparison of SOD in cores, an in situ respirometer and an in situ tunnel respirometer in English streams [25], showed that both the core and the in situ respirometer method underestimated SOD compared to the rates obtained with the tunnel respirometer and from mass balance calculations, the results from the laboratory core method showing the greatest percent deviation. In their study, the mass balances were more uncertain than in our study, however, as correction for re-aeration had to be done to be able to make the comparison with the other methods. Nevertheless, their results clearly indicate that the tunnel method, allowing horizontal flow over the sediment and in the surface sediment, was superior to the others. There are, however, three serious problems with this method: 1) the tunnel cannot be placed in the stream without disturbing the sediment, 2 ) the water volume in the tunnel is difficult to measure, and 3 ) the tunnel must be long enough e.g., 20-30 $\mathrm{m}$, depending on sediment SOD to trace significant changes in the oxygen concentration from upstream to downstream. An alternative is to use flow-through chambers [26], perhaps positioned at the stream banks to minimise the effect of transport and to create more realistic light conditions [7].

\section{CONCLUSIONS}

Our results demonstrate 1) that lab measurements of SOD substantially underestimate the actual SOD in natural streams, not least when the sediment is organic rich and easy to resuspend; and 2) that the horizontal flow-through systems, perhaps positioned at the bank of the stream, may provide more realistic SOD uptake values.

\section{ACKNOWLEDGEMENTS}

We wish to thank Finn Pedersen for his assistance during the field work. We are indebted to Finn Pedersen, Hanne Møller and Annemette Thorsteinsson for their technical assistance and Anne Mette Poulsen for her great manuscript editing work. This work was supported by the TÜBITAK BIDEB2232 program (Project 118C250).

\section{REFERENCES}

1. Edwards R.W., and Rolley H.L.J. (1965) Oxygen consumptions of river muds. J. Ecol., 53, 1-19. https://www.jstor.org/stable/pdf/225762.pdf

2. Belanger T.V. (1981) Comparison of benthic oxygen demand measurement techniques. Florida Scientist, 44, 204-218

3. Todd M.J., Vellidis G., Lowrance R.R., and Pringle C.M. (2009) High sediment oxygen demand within an instream swamp in Southern Georgia: Implications for low dissolved oxygen levels in coastal blackwater streams. J. Am. Wat. Res. Ass., 45, 1493-1507. https://doi.org/10.1111/ j.1752-1688.2009.00380.x

4. Hogsett M., and Goel R. (2013) Dissolved oxygen dynamics at the sediment-water column interface in an urbanized stream. Environ. Eng. Sci., 30, 594-606. https://doi.org/10.1089/ees.2012.0467

5. Tan X., Hou E., Zhang Q., et al. (2021) Benthic metabolism responses to environmental attributes at multiple scales and its linkage to algal 
community structure in streams. Hydrobiologia, 848, 5067-5085. https://doi.org/10.1007/ s10750021-04693-9

6. Juckers M., Williams G.J., and Xenopoulos M.A. (2013) Land-use effects on resource net flux rates and oxygen demand in stream sediments. Freshwat. Biol., 58,1405-1415. http://dx.doi. org/10.1111/fwb.12136

7. Prahl C., Jeppesen E., Sand-Jensen K., et al. (1991) Continuous-flow system for measuring in vitro oxygen and nitrogen metabolism in separated stream communities. Freshwat. Biol., 26, 495506. doi:10.1007/s10531-004-0694-z

8. Bott T.L., Brock J., Cushing. C.E., et al. (1978) A comparison of methods for measuring primary productivity and community respiration in streams. Hydrobiologia, 60, 3-12. https://doi.org/10.1007/ BF00018681

9. Wilson G.T., and McLeod N. (1974) A critical appraisal of empirical equations and models for the prediction of the coefficient of respiration of deoxygenated water. Wat. Res., 8, 341-366. https://doi.org/10.1016/0043-1354(74)90048-7

10. Edberg N. (1976) Oxygen consumption of sediment and water. Vatten, 1, 2-12.

11. Berg K. (1943) Physiographical studies on the River Susaa. Fol. Limnol. Scand., 1, 1-174.

12. https://serc.carleton.edu/microbelife/research_ methods/environ_sampling/oxygen.html

13. Kamp-Nielsen L. (1974) Mud-water exchange of phosphate and other ions in undisturbed sediment cores and factors affecting the exchange rates. Arch. Hydrobiol., 73, 218-237. https://doi. org/10.1127/archiv-hydrobiol/73/1974/218

14. Baity H.G. (1938) Some factors affecting the aerobic decomposition of sewage and sludge deposits. Sew. Works. Journ., 10, 539-568. https:// www.jstor.org/stable/25030772

15. Edberg N., and Hofsten B. (1973) Oxygen uptake of bottom sediments studied in situ and in the laboratory. Wat. Res., 7, 1285-1294. https://doi. org/10.1016/0043-1354(73)90005-5

16. Downing L. (1967) The effect of pollution on the oxygen balance of rivers. Reprint no. 517. Wat. Poll. Res. Laboratory, Stevenage.
17. Baumgardner K.R. (1966) Oxygen balance in a stream receiving domestic and oil refinery effluents. PhD-thesis, Oklahoma State University, Oklahoma. https://www.proquest.com/ docview/302233915?pq-origsite=gscholar\&fromo penview=true

18. Rolley H.L.J., and Owens M. (1967) Oxygen consumption rates and some chemical properties of river muds. Wat. Res., 1, 759-766. https://doi. org/10.1016/0043-1354(67)90018-8

19. Hargrave B.T. (1969) Similarity of oxygen uptake by benthic communities. Limnol. Oceanogr., 14, 801805. https://doi.org/10.4319/lo.1969.14.5.0801

20. Oldaker W.H., Burgum A.A., and Pahren H.R. (1968) Pilotplant study of benthic oxygen demand of river bottom sediments. J. Wat. Poll. Contr. Fed., 40, 1688-1701. https://www.jstor.org/ stable/25036128

21. Ogumrombi J.A., and Dobbins W.E. (1970) The effects of benthal deposits on the oxygen resources of natural streams. J. Wat. Poll. Contr. Fed., 42, 538-552.

22. Bouldin D.R. (1968) Models for describing the diffusion of oxygen and other mobile constituents across mud-water interface. J. Ecol., 56, 77-87. https://doi.org/10.2307/2258068

23. McDonnel A.J., and Hall, S.D. (1967) Effect of environmental factors on benthal oxygen uptake. $22^{\text {nd }}$ Industrial Waste Conference 1967, Part I, Purdue University: 414-428.

24. Mackenthun A.A., and Stefan H.G. (1995) Effects of flow velocity on sediment oxygen demand: Experimental results. Project report no. 371. University of Minnesota, St Anthony Falls Hydraulic Laboratory, Minneapolis, Minnesota, 51 p. https://hdl.handle.net/11299/109286

25. James A. (1974). The measurement of benthal respiration. Wat. Res., 8, 955-959. https://doi. org/10.1016/0043-1354(74)90110-9

26. Jeppesen E. (1982) Diurnal variation in the oxygen uptake of river sediments in vitro by use of the continuous flowthrough systems. Hydrobiologia, 91, 189-195. https://doi.org/10.1007/BF02391935 